\title{
Visual disturbances in patients with pituitary tumors and early improvement of visual acuity and visual field defects after resection of pituitary tumors.
}

\begin{abstract}
Hamid Akbar Shaikh1, Safdar Hussain Arain², Lal Rehman ${ }^{3}$, Abdul Sattar M Hashmi ${ }^{4}$
\end{abstract}
\begin{abstract}
Objective: The aim behind this study was to determine the frequency of visual field and visual acuity disturbances before resection and improvement after resection of pituitary tumors in patients. Study Design: Observational study. Setting: Neurosurgery Department of Jinnah Post Graduate Medical Center, Karachi. Period: August 2015 to August 2016. Material \& Methods: A total of 30 patients presented with headache and visual deterioration and diagnosed as pituitary adenoma at neurosurgery OPD, ward and ER were included through a consecutive purposive sampling technique. The detailed visual and ocular analysis (visual acuity, visual field, and extra ocular movements) carried out at time of admission and postoperatively. Tumor was removed by consultant neurosurgeon through trans-sphenoidal approach. SPSS version 17.0 was used to analyze the collected data. Results: A total of 30 cases of pituitary adenoma were included. The average age of the patients was $34.5 \pm 10.8$ years and among them 17 $(56.7 \%)$ were males and $13(43.3 \%)$ were females. Pre-operative assessment of the mean deviation of visual function was $-8.21 \pm 6.10 \mathrm{~dB}$ which is significantly improved to $-4.6 \pm 3.9 \mathrm{~dB}$ post-operatively $(P<0.0001)$. While pre-operative Visual Acuity (logMAR) was $0.3 \pm 0.26$ and post-operative $0.21 \pm 0.2(P<0.0001)$. Conclusion: Scientific observation from our study has shown that more than $90 \%$ of the patients suffering from pituitary adenomas experience visual impairment which can be improved to significant extent if treated with trans-sphenoidal surgical resection of the tumor.
\end{abstract}

Key words: $\quad$ Pituitary Adenoma, Visual Disturbance, Visual field, MRI.

Article Citation: Shaikh HA, Arain SH, Rehman L, Hashmi ASM. Visual disturbances in patients with pituitary tumors and early improvement of visual acuity and visual field defects after resection of pituitary tumors. Professional Med $\mathrm{J}$ 2021; 28(9):1257-1261. https://doi.org/10.29309/TPMJ/2021.28.09.6727

\section{INTRODUCTION}

Epidemiological studies have reported worldwide burden of pituitary adenomas around $16 \%$. Incidental pituitary tumors are found in approximately $15 \%$ of autopsies. Based on the classification pituitary adenomas are most often benign and with time they may involve and metastasize to the surrounding tissues including visual pathway and leading to the development of visual impairment. ${ }^{1-3}$

Patients who are suffering from Adenomas of pituitary glands showed varying range in clinical presentation from decrease in visual acuity to no vision at all. Variation can be seen in such patients in the prevalence raging from $37 \%$ to $96 \% .{ }^{4}$ Most of the conducted studies have shown that bitemporal hemianopia is the most prevalent visual field defect observed in patients with pituitary adenomas. ${ }^{1,5,6}$

Despite advances in radiation therapy and pharmacological treatment, surgery remains the first-line treatment, except for prolactinomas. ${ }^{7}$ The presence of visual abnormalities is one of the main indications for surgical resection and chiasmatic decompression. International guidelines recommend surgery is the most reliable treatment with very high success rate.

\section{MATERIAL \& METHODS}

A prospective observational study has been conducted through convenient purposive sampling technique in a department of Neurosurgery Jinnah Postgraduate Medical Centre Karachi between the periods of one year 
from $21^{\text {th }}$ August 2015 to $20^{\text {th }}$ August 2016. All the patients of both gender and age ranged from 18 years to 71 years those who presented with complain of headache and disturbance in visual field in neurosurgery OPD, ward, or Emergency which were diagnosed as a case of pituitary adenoma were included in this study after getting their informed and written consent.

A detailed history of patients was taken along with detailed visual and ocular examination including visual acuity, visual field, and extra ocular movements were carried out at the time of admission and after performing operation.

To evaluate the size and the invasion of the adenoma, all patients underwent magnetic resonance imaging (MRI), with and without administration of the intravenous contrast agent prior to surgery. Tumor size was classified in three categories according to tumor diameter: microadenoma $(<10 \mathrm{~mm})$; macroadenomas (>10 mm); and giant adenoma (>40 mm).

Patients stayed two days prior to operation and 5-7 days postoperatively, depending upon the stability and recovery. Trans-sphenoidal approach was taken for the removal of pituitary gland tumor. Cure was defined as a resolution of the clinical symptoms and signs and, where appropriate, normalization or improvement of the underlying preoperative in visual impairment.

We have used Statistical Package for the Social Sciences (SPSS) version 16 for data entry and its analysis. Continuous variables like age and visual parameters were analyzed as mean \pm Standard deviation.

\section{RESULTS}

A total of 30 cases of pituitary adenoma were included in this study presented with headache and visual symptoms. Mean \pm SD of age was $34.5 \pm 10.8$ years age ranged from $18-71$ years. Majority of cases were cases belonged to age between $21-40$ years, $(N=20,66.7 \%)$. Figure-1

Gender distribution showed male preponderance (male: female $=1.3: 1$ ), out of 30 cases 17
$(56.7 \%)$ were males and $13(43.3 \%)$ were females. Figure-2

Majority $27(90 \%)$ of cases presented with visual disturbance followed by headache $23(76.7 \%)$ and $3(10 \%)$ cases were presented ophthlamoplegia. Figure-3

Pre-operative visual acuity is presented in Figure-4. A total of 29 (48.3\%) cases had visual acuity 6/60 - NPL while 19 (31.7\%) cases had visual acuity $6 / 18$ to $6 / 36$ and $12(20 \%)$ cases had visual acuity $6 / 6$ to $6 / 12$.

Before the operation, an experienced ophthalmologist was assigned to record the data relevant to the study objects. Comparison was performed before the operation visual function and after that. A significant improvement has been observed when data were compared preoperatively with post-operative visual functions, $-8.21 \pm 6.10 \mathrm{~dB}$ and $-4.6 \pm 3.9 \mathrm{~dB}$ $(P<0.0001)$, respectively. While pre-operative Visual Acuity (log MAR) was $0.3 \pm 0.26$ and postoperative $0.21 \pm 0.2(P<0.0001)$, Table-l.

Pre-operative abnormal visual field presented in Table-II. Out of 60 eyes of 30 cases, 32 (53.3\%) eyes with bitemporal hemianopia (BTH), Three quadrant Field defects was found in 14 (23.3\%) cases, $10(16.7 \%)$ cases with hemianopia and 4 $(6.7 \%)$ cases with atypical field defect.

The results of visual acuity, after the procedure showed that significant number $23 \quad(38.3 \%$, p-0.03) of patients had visual acuity $6 / 6$ to $6 / 12$, and $30(50 \%, p-0.04)$ patients had visual acuity $6 / 18$ to $6 / 36$, while only $7(11.7 \%)$ patients having visual acuity $6 / 60-$ NPL. Overall improvement in visual acuity was $43.3 \%$. Table-III

Regarding post-operatively visual field defects, 35 (58.3\%) eyes were improved and 25 (41.7\%) of eyes were unchanged Table-IV. 


\begin{tabular}{l|c|c|c|}
\hline \multicolumn{1}{|c|}{ Parameter } & Pre-Operatively & Post-Operatively & P-Values \\
\hline Mean Deviation (dB) & $-8.21 \pm 6.10$ & $-4.6 \pm 3.9$ & $<0.0001$ \\
\hline Visual Acuity (logMAR) & $0.3 \pm 0.26$ & $0.21 \pm 0.2$ & $<0.0001$ \\
\hline & Table-I. Pre and postoperative visual function. & \\
dB = Decibel & & \\
logMAR = Logarithm of the Minimum Angle of Resolution. & & \\
\end{tabular}

\begin{tabular}{|l|c|c|}
\hline & Number of Eyes & Percentages \\
\hline BTH & 32 & $53.3 \%$ \\
\hline Three quadrant field defects & 14 & $23.3 \%$ \\
\hline Hemianopia & 10 & $16.7 \%$ \\
\hline Atypical field defect & 4 & $6.7 \%$ \\
\hline & Table-II. Pre-operative abnormal visual field. N=60 eyes & \\
\hline BTH: Bi-temporal hemianopia. & &
\end{tabular}

\begin{tabular}{|l|c|c|c|}
\hline & Pre-Operatively & Post-Operatively & P-Values \\
\hline $6 / 6-6 / 12$ & $12(20 \%)$ & $27(45 \%$ & 0.1 \\
\hline $6 / 18-6 / 36$ & $19(31.7 \%)$ & $30(50 \%)$ & 0.04 \\
\hline $6 / 60-$ NPL & $29(48.3 \%)$ & $3(5 \%)$ & $<0.0001$ \\
\hline \multicolumn{2}{|l|}{ NPL = No Perception of Light. } \\
\hline
\end{tabular}

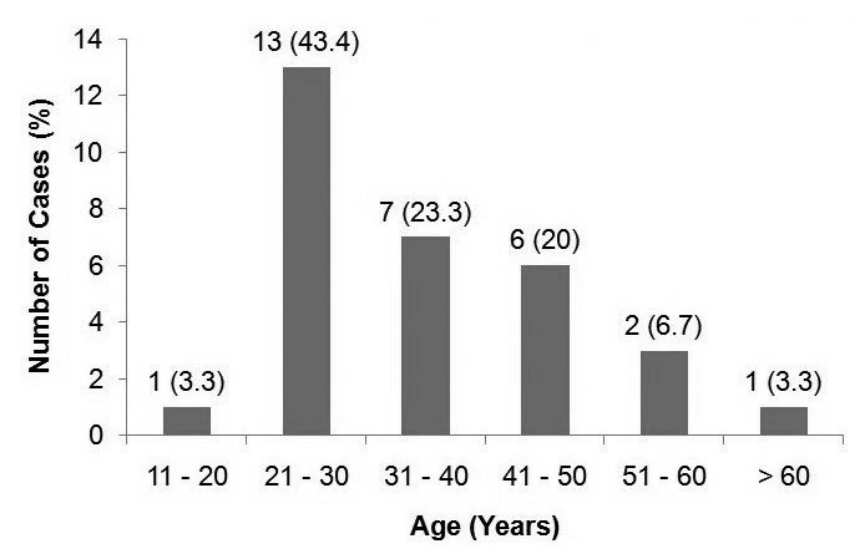

Figure-1. Age Distribution $\mathbf{n}=\mathbf{3 0}$

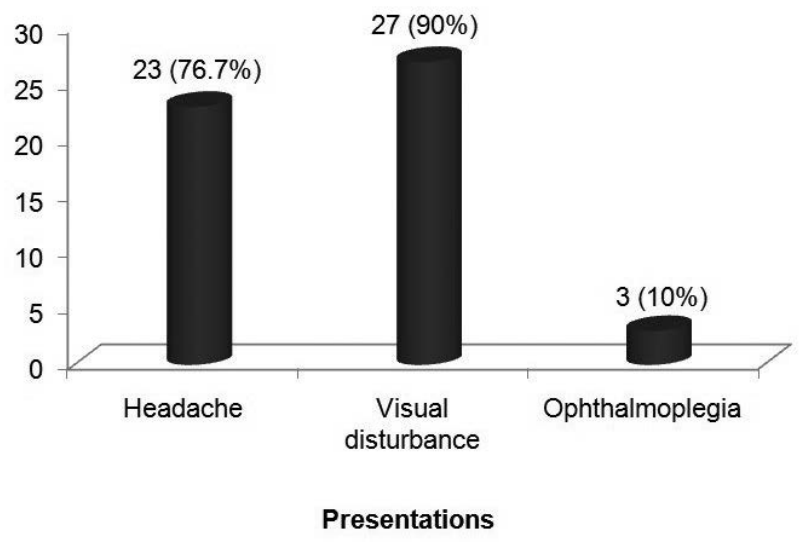

Figure-3. Presenting symptoms $n=30$

Categorical distribution of age of our study participants.
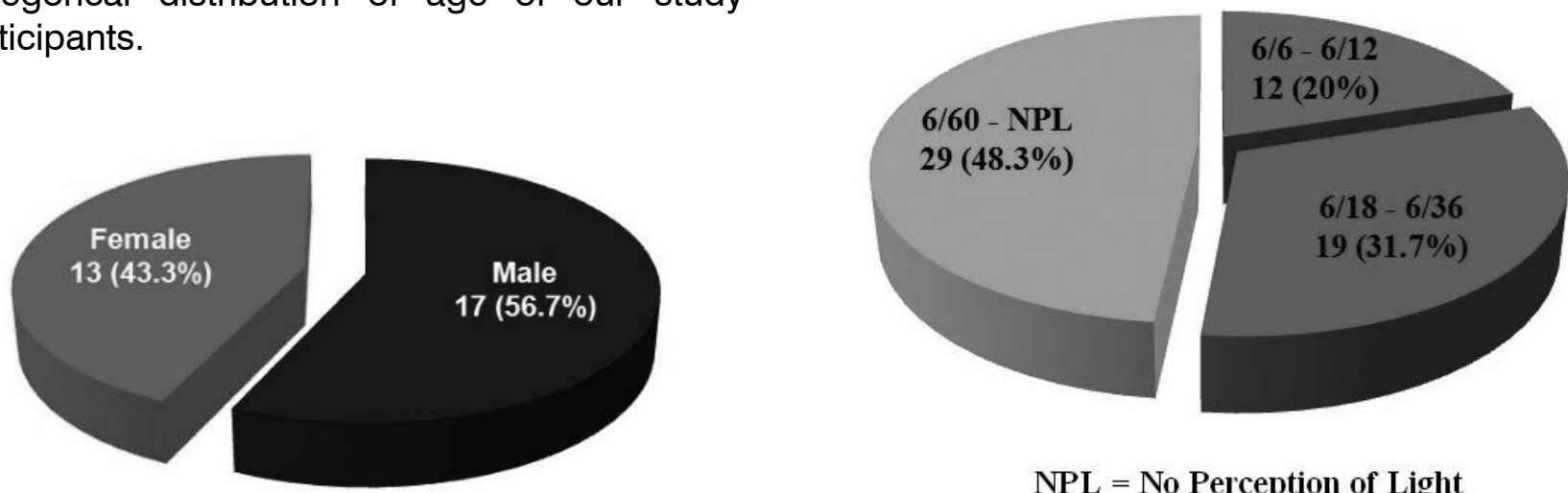

NPL $=$ No Perception of Light

Figure-2. Gender wise distribution of the study subjects.

Figure-4. Pre-operative visual acuity $n=30$ (60 Eyes) 


\section{DISCUSSION}

Variety of visual presentations of pituitary tumors have been reported because of its slow growing nature, including absence of clinical symptoms or deterioration of visual acuity, visual field affection, and partial or complete ophthlamoplegia and optic atrophy. The surgical procedure which we have chosen in our study was amongst the most reliable for the resection of pituitary tumors through sphenoidal surgical resection. After surgical removal of the tumor the complete recovery takes some times from initial improvement of the symptoms to finally remyelination of the decompressed optic pathways. Worldwide most of the surgeons chose trnas-sphenoidal approach to treat such cases because of its lower complication rates and higher success rate..$^{8-11}$

In this study, 30 patients of pituitary adenoma were studied presented with headache and visual symptoms. Mean $\pm S D$ of age of patients was $34.5 \pm 10.8$ year with male: female was 1.3: 1. A study from India studied eighteen patients with pituitary adenomas underwent ophthalmic and VF assessment before and after transsphenoidal surgical resection, they reported mean age 35.1 \pm 9.9 years and $M$ : $F$ was 1.25: 1 which is similar to this study..$^{12}$ Another study from Bangladesh compared pre and postoperative visual parameters of 30 cases of Pituitary adenoma underwent transsphenoidal surgery, they reported average age $36.2 \pm 13.7$ years with $\mathrm{M}: \mathrm{F}$ was 1.1:1 which are in agreement with this study. ${ }^{13}$

In this study $90 \%$ of patients presenting with visual symptoms of pituitary adenoma while $76.7 \%$ cases presented with headache and $10 \%$ cases were presented with ophthlamoplegia Elgamal et al. ${ }^{14}$ Found $17 \%$ eyes presented with loss of vision due to pituitary adenomas. Dallapiazza RF and colleagues ${ }^{15}$ reported that, more than $50 \%$ of patients presented with visual disturbance.

In this study visual function parameters were recorded pre and post operatively. Pre-operative mean deviation $(\mathrm{dB})$ was $-8.21 \pm 6.10 \mathrm{~dB}$ which is significantly improved to $-4.6 \pm 3.9 \mathrm{~dB}$ postoperatively $(P<0.0001)$. While pre-operative
Visual Acuity (logMAR) was $0.3 \pm 0.26$ and postoperative $0.21 \pm 0.2(P<0.0001)$. Previously conducted Indian study has shown significant improvement of visual functions from $-14.28 \mathrm{~dB}$ to $-11.32 \mathrm{~dB}$ after the patients were treated with trans-sphenoidal procedure. ${ }^{12}$

Regarding improvement in visual acuity present study reported overall improvement in visual acuity was $43.3 \%$ and $56.7 \%$ remaining unchanged. Bangladeshi study reported improvement in visual acuity was $40 \%$ and $55 \%$ eyes remained stable. ${ }^{12}$ Postoperatively, visual field defects improved 35 eyes (58.3\%) leading to normal fields. Rest of the patients showed relative improvement or remained unchanged after surgery. An Indian study reported postoperative visual field defects improved $50 \%$ eyes while $50 \%$ eyes showed relative improvement after surgery. ${ }^{12}$

In summary, the main parameter for visual outcomes in patient with pituitary adenoma is better preoperative visual status. If patients have better preoperative ophthalmological status then their visual outcome would be better after surgery in pituitary adenoma.

\section{CONCLUSION}

Our study has shown that more than $90 \%$ of the patients suffering from pituitary adenomas experience visual impairment that can be improve to significant extent if treated with transsphenoidal surgical resection of the tumor.

\section{Copyright $@ 23$ May, 2018.}

\section{REFERENCES}

1. Kim TG, Jin KH, Kang J. Clinical characteristics and ophthalmologic findings of pituitary adenoma in Korean patients. International ophthalmology. 2019 Jan; 39(1):21-31.

2. Schuss P, Hadjiathanasiou A, Klingmüller D, Güresir Á, Vatter $H$, Güresir $E$. Transsphenoidal pituitary surgery: Comparison of two sellar reconstruction techniques and their effect on postoperative cerebrospinal fluid leakage. Neurosurgical review. 2018 Oct; 41(4):1053-8.

3. Wildemberg LE, Glezer A, Bronstein MD, Gadelha MR. Apoplexy in nonfunctioning pituitary adenomas. Pituitary. 2018 Apr; 21(2):138-44. 
4. Sipos B. Neuroendocrine neoplasms of the auditory, olfactory, and visual sensory organs. Der Pathologe. 2018 May 1; 39(3):255-63.

5. Aljabri Ks, Bokhari SA, Assiri FY, Alshareef Ma, Khan $\mathrm{Pm}$. The epidemiology of pituitary adenomas in a community-based hospital: A retrospective single center study in Saudi Arabia. Ann Saudi Med 2016 Sep; 36(5):341-5.

6. Chinezu R, Fomekong F, Lasolle $\mathrm{H}$, Trouillas J, Vasiljevic A, Raverot G, Et Al. Risks and benefits of endoscopic transsphenoidal surgery for nonfunctioning pituitary adenomas in patients of the ninth decade. World Neurosurg 2017 Oct; 106:315-21.

7. Muskens Is, Zamanipoor Najafabadi Ah, Briceno V, Lamba N, Senders JT, Van Furth WR, et al. Visual outcomes after endoscopic endonasal pituitary adenoma resection: A systematic review and metaanalysis. Pituitary 2017 Oct; 20(5):539-52.

8. Rutkowski MJ, Alward RM, Chen R, Wagner J, Jahangiri A, Southwell DG, et al. Atypical pituitary adenoma: A clinicopathologic case series. J Neurosurg 2017 Jun 9; 1-8.

9. Luomaranta T, Raappana A, Saarela V, Liinamaa MJ. Factors affecting the visual outcome of pituitary adenoma patients treated with endoscopic transsphenoidal surgery. World neurosurg 2017 Sep; 105:422-31.
10. Thotakura AK, Patibandla MR, Panigrahi Mk, Addagada GC. Predictors of visual outcome with transsphenoidal excision of pituitary adenomas having suprasellar extension: A prospective series of $\mathbf{1 0 0}$ cases and brief review of the literature. Asian j neurosurg 2017 Jan; 12(1):1-5.

11. Kerrison JB, Lynn MJ, Baer CA, Newman SA, Biousse V, Newman NJ. Stages of improvement in visual fields after pituitary tumor resection. Am j ophthalmol 2000 Dec; 130(6):813-20.

12. Dhasmana R, Nagpal RC, Sharma R, Bansal KK, Bahadur $\mathrm{H}$. Visual fields at presentation and after trans-sphenoidal resection of pituitary adenomas. $J$ Ophthalmic VIS Res 2011 Jul; 6(3):187-91.

13. Seuk JW, KIM CH, Yang MS, Cheong JH, KiM JM. Visual outcome after transsphenoidal surgery in patients with pituitary apoplexy. J Korean Neurosurg Soc 2011 JUN; 49(6):339-44.

14. Al-Habib AF, Jamjoom ZA, Elgamal ea. Pattern of patient referrals to a tertiary neurosurgery center in the central region of Saudi Arabia. Neurosciences (Riyadh) 2012 Jul; 17(3):271-3.

15. Dallapiazza RR, Grober Y, Starke RM, Laws EE, JR., Jane $J A$, JR. Long-term results of endonasal endoscopic transsphenoidal resection of nonfunctioning pituitary macroadenomas. Neurosurgery 2015 JAN; 76(1):42-52.

\begin{tabular}{|c|c|c|c|}
\hline \multicolumn{4}{|c|}{ AUTHORSHIP AND CONTRIBUTION DECLARATION } \\
\hline Sr. \# & Author(s) Full Name & Contribution to the paper & Author(s) Signature \\
\hline 1 & Hamid Akbar Shaikh & & \\
\hline 2 & Safdar Hussain Arain & All Authors have contributed & \\
\hline 3 & Lal Rehman & equally. & \\
\hline 4 & Abdul Sattar M Hashmi & & \\
\hline
\end{tabular}

